\title{
Investigation of Aqueous and Non-Aqueous Phase Liquids Migration in Fractured Double-Porosity Soil
}

\author{
Loke Kok Foong $^{1 *}$, Norhan Abd Rahman ${ }^{2}$ \\ ${ }^{1}$ Faculty of Civil Engineering, Universiti Teknologi Malaysia, Johor, Malaysia \\ 2Centre of Tropical Geoengineering, Faculty of Civil Engineering, Universiti Teknologi Malaysia, Johor, Malaysia \\ *Corresponding author: edwinloke84@yahoo.com
}

\begin{abstract}
The issue of leakage from underground storage tank and spillage of contaminate liquids can contribute to the aqueous and non-aqueous phase liquids contamination into the groundwater, resulting in groundwater pollution and rendering the quality of groundwater unsafe for consumption. Ensuring availability and sustainable management of water and sanitation for all was the goal and target in the 2030 agenda for sustainable development, consisting of a plan of action for people, planet and prosperity of the United Nations. This paper is intended to investigate the aqueous and non-aqueous phase liquid migrations in the fractured double-porosity soil, which become important for sustainability of groundwater utilisation and a comprehensive understanding of the pattern and behaviour of liquid migration into the groundwater. For this aim, an experiment model was conducted to study the pattern and behaviour of aqueous and non-aqueous phase liquid migration in fractured double-porosity soil using digital image processing technique. Outcome of the experiments show that the fractured double-porosity soil has faster liquid migration at the cracked soil surface condition compared to intact soil surface. It can concluded that the factors that significantly influence the aqueous and non-aqueous phase liquids migration was the soil sample structure, soil sample fractured pattern, physical interaction bonding between the liquid and soil, and the fluid capillary pressure. This study demonstrates that the hue saturation intensity contour plot of liquids migration behaviour can provide detailed information to facilitate researchers and engineers to better understand and simulate the pattern of liquids migration characteristics that influence the groundwater resources.
\end{abstract}

Keywords—Granular Material, Vibration, Groundwater Contamination, Liquid Migration, Digital Image Analysis.

\section{INTRODUCTION}

$\mathrm{N}$ atural disasters such as flash flood and earthquake events

recently reported at Ranau, Sabah [1] and climate change spurred by phenomena such as El-Nino have had an influence on national development activity, which lead to a negative impact on health issue and geo-environment. Groundwater contamination is one of the most challenging geoenvironmental issues encountered in many countries. The issue of leakage from underground storage tank and spillage of hydrocarbon liquid can contribute to the contamination of non-aqueous phase liquids (NAPLs) and aqueous phase liquids (APLs) into the groundwater, resulting in groundwater pollution and rendering the quality of groundwater unsafe for drinking and agriculture. The flow rate and phenomena of the migration of NAPLs and APLs into the groundwater resources would be more complicated under the effect of earthquake vibration on double-porosity soil. Vibration leads to cracked soil, rearrangement of soil structure, unstable soil structure and fractured soil deformation [2]. These problems need to be overcome by both engineers and researchers worldwide to ensure the sustainability of geo-environmental and groundwater resources. Deformable double-porosity soil has been identified as having two specific sub-region scales with soil transforming characteristics, and a greater understanding with respect to NAPLs migration under the phenomena of fractured double-porosity soil is required. Dangerous reproductive toxic chemicals have made actual on- site study infeasible, and have been practically replaced by physical experimental model simulations. The most critical contaminants involve the petroleum type hydrocarbons such as toluene, which has been used in this study, and which can be classified as light non-aqueous phase liquids whose density is less than water.

The structure of the soil affects the flow rate and characteristic of liquids migration. It is well known that soil is typified by many different structures, and that soils characteristics are roughly not homogeneous. Fractured soil reduced the intact soil shear strength and increased the hydraulic conductivity [3]. Krisnanto et al. [4] stated that the cracked soil played an essential role in the flow of liquids through problematic soil. The hydrological behaviour and mechanical properties in fractured soil are significantly changed [3]. It is widely acknowledged that the soil with intraaggregate and inter-aggregate pores for double-porosity soil display pore-size bimodal distribution that can found in agricultural tops-soils and compacted soil [5] and [6]. According to Sa'ari et al. [7], the double-porosity soils have different hydraulic properties of two sub-region media due to different pore size characteristics. Existing research by Lakeland et al. [8] had demonstrated that liquefaction is not a strictly undrained process via first principles analysis, but in fact observation of numerous earthquake events shows that the interplay between soil rearrangement, liquid migration, and permeability changes have led to loss of strength. The fracture porosity formation were characterized by water-bearing formations where groundwater flows along the fracture solid 
rock, while a fracture is created as rock mass is broken down due to tectonic force [9].

Research by Barenblatt et al. [10] found that the overlapping continuum technique had been the basis theory for the doubleporosity soil. Moreover, Fredlund et al. [3] show that fractured soils based on a continuum mechanics approach is used for inception of unsaturated liquid storage and conductivity functions. In addition, the dual-continuum method is capable of dealing more methodically with fracture matrix interplay compared to discrete-fracture model [3]. Therefore, this study applied the model concept with the soil that overlaps the three continuums of fracture, primary, and secondary porosity features developed by Loke et al. [11]. The double-porosity characteristics in soil could be created in the laboratory, where most of the studies relating to double-porosity soil were carried out by Lewandowska et al. [12]. Bagherieh et al. [13], conducted one-dimensional drying and consolidation experiments on laboratory-prepared double-porosity kaolin soil sample. Recently, (Sa'ari et al. [7]; Loke et al. [11]; Alazaiza et al. [14]; Ngien et al. [15]; Sitthiphat and Siam [16]; and Peng et al. [17]) have conducted physical experiments on double-porosity soil media. The previous listed research has contributed to the knowledge of soil characteristics in doubleporosity soil, but the studies were limited to intact doubleporosity and the reaction such as vibration effect on the double-porosity soil was never applied.

Luciano et al. [18] identified that a powerful technique in most research fields was image analysis method, which was used to investigate the complicated behaviour of contaminants and determination of liquid saturation rate. Therefore, this study used digital image analysis to understand and analyze the liquid migration in fractured double-porosity soil. Based on the overview by Agaoglu et al. [19], the experiment involved noninvasive imaging techniques, which used observation and characterization of multiphase system for greater precision. Furthermore, Cnudde and Boone [20] proved that image analysis is a reliable technique for rock pore space direct imaging and direct investigation of liquid migration. Therefore, a number of researchers [7], [14]-[17], and [21]-[23] have carried out image analysis techniques for liquid migration experiment. As mentioned by Maas and Hampel [24], image analysis technique in civil engineering field was regularly used to study the object flow absorption and liquid migration of small properties specific to structure crack extension. Thus, the porosity and cracked soils are difficult to visualize by naked eye and for this problem, digital image processing technique was acceptable for use in this study to observe and monitor liquid migration in fractured double-porosity soil.

The widespread problem of difficulty gathering reliable data concerning liquid migration characteristics and the physical experiments model will go a long way in the effort to understand and observe such problem [25]. Previous research by Kristnanto et al. [4] presented a significant comprehensive understanding of the flow characteristics through cracked soil and suggested that further experimental study on more complex crack network is required to study the water flow rate. Therefore, a physical experimental model was conducted to study the characteristics of APLs and NAPLs migration in deformable double-porosity soil under the vibration effect by using digital image processing technique (DIPT). Thus, to achieve the purpose of this study, several objectives based on the literature were (i) to determine the behavior of APLs and NAPLs migration in fractured double-porosity soil using digital image processing technique, (ii) to differentiate the flow rate and pattern of APLs and NAPLs migration in fractured double-porosity. This study covered the double-porosity aggregated soil medium vibrated by using a vibratory table involving a special assemble acrylic glass soil column. The liquid migrations were observed in a $100 \mathrm{~mm}$ height fractured soil sample in acrylic glass circular column. The aggregated soil sample mixed with $30 \%$ water was added to dry kaolin S300 soil. Toluene and distilled water were used as a liquid source for NAPLs and APLs, respectively. Red powder was used to dye the Toluene and distilled water to intensify the migration observation. Dyed Toluene and distilled water with $70 \mathrm{ml}$ was poured instantaneously on top of the soil surface for each aggregated soil sample. The image analysis was accomplished by using Surfer programme and Matlab routine to analyse the liquid migration pattern and behaviour.

\section{METHOD}

The soil sample preparation, experimental setup, and digital image processing setup used in this study were briefly discussed in subsequent sections.

\section{A. Soil Sample Preparation}

To create double-porosity, commercially available kaolin soil S300 was used in this study as sample material. British Standard BS 1377-2:1990 and BS 1377-5:1990 were used to test the kaolin soil S300 soil properties for the purpose to obtain particle size distribution, Atterberg limits, solid particle density and saturated permeability of the kaolin soil. The kaolin soil S300 was classified under the Unified Soil Classification System (USCS) as silt with low plasticity (ML) based on the value of particle size distribution and Atterberg limits. The properties of kaolin soil sample S300 are shown in Table 1.

Table 1. Kaolin soil S300 properties

\begin{tabular}{lc}
\hline PROPERTY & VALUE \\
\hline Liquid Limit (\%) & 41.00 \\
Plastic Limit (\%) & 28.00 \\
Plasticity Index (\%) & 13.00 \\
Particle Density $\left(\mathrm{Mg} / \mathrm{m}^{3}\right)$ & 2.65 \\
Sand: $2 \mathrm{~mm}$ to $0.06 \mathrm{~mm}(\%)$ & 3 \\
Silt: $0.06 \mathrm{~mm}$ to $0.002 \mathrm{~mm}(\%)$ & 92 \\
Clay: Smaller than $0.002 \mathrm{~mm}(\%)$ & 5 \\
USCS Classification & $\mathrm{ML}$ \\
Saturated Permeability, $\mathrm{K}_{\text {average }}(\mathrm{m} / \mathrm{s})$ & $5.41 \times 10^{-9}$ \\
\hline
\end{tabular}

As previously explained, the method established by Bagheriah et al. [13] was used to prepare the aggregated soil sample. The dried kaolin powder was first mixed with $30 \%$ of moisture content to prepare the aggregated soil sample such as APLs and NAPLs for sample 1 and sample 2, respectively. The selection of moisture content in this experiment was based on the liquid limit, and the optimum moisture content for kaolin soil sample in this study was $27 \%$. Thereafter, in a cool condition, the mixture was cured and kept in a re-sealable plastic bag for a minimum 24 hours, with the air in the plastic bag 
removed before sealing to avoid the moisture content evaporated. After that, the mixture was broken by hand and passed through a $2.36 \mathrm{~mm}$ sieve for both samples to obtain kaolin granules. Then, granules were transported in acrylic soil column and the soil granules compressed to a height of $100 \mathrm{~mm}$ using a compression machine. The rationale of $100 \mathrm{~mm}$ sample height was to ensure the uniformity throughout the soil sample depth. The prepared aggregated soil sample is shown in Figure 1. The falling head permeability test was carried out to obtain the average permeability of the aggregate soil sample as shown in Table 1 for the average permeability $\left(\mathrm{K}_{\text {average }}\right)$ value.

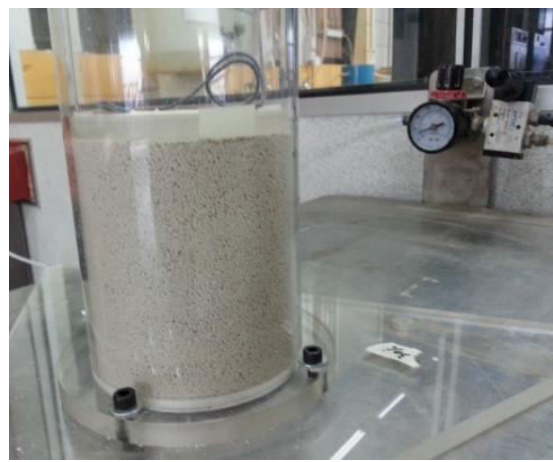

Figure 1. The prepared kaolin soil sample

The physical laboratory experiments were implemented in special design circular acrylic soil column with dimension of $300 \mathrm{~mm}$ high $\mathrm{x} 100 \mathrm{~mm}$-outer diameter and $94 \mathrm{~mm}$-inner diameter. The acrylic soil column with aggregated soil sample was fitted and bolted on the vibratory table in order to prevent any freedom of movement of the acrylic soil column. The vibratory table setup to vibrate the aggregated soil sample was developed by Loke et al. [11] as shown in Figure 2 .

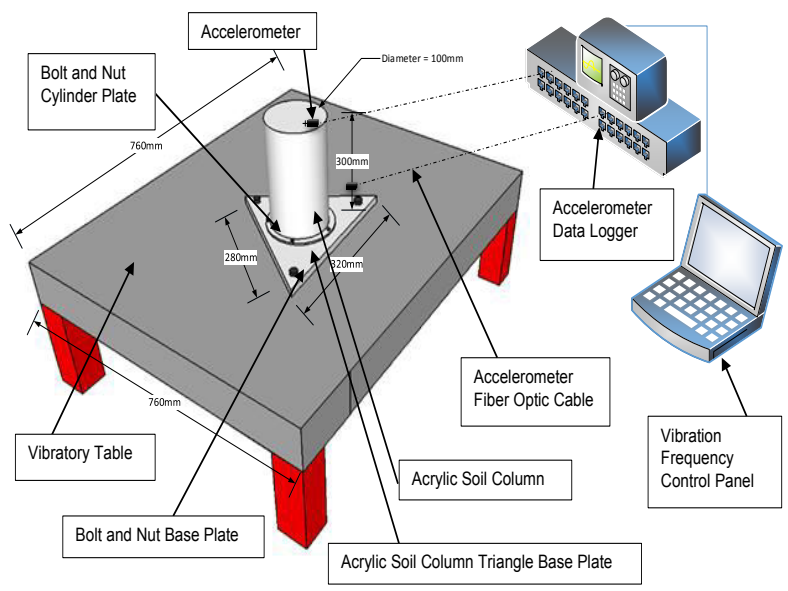

Figure 2. 3D diagram of vibratory table setup [11]

The vibration frequency of the vibratory table was set at $0.98 \mathrm{~Hz}$ and a vibration period of 60 seconds has been applied to vibrate the aggregated soil sample based on the method established by Loke et al. [11]. The results of fractured soil pattern for sample 1 and sample 2 before and after vibration process are exhibited in Figure 3.

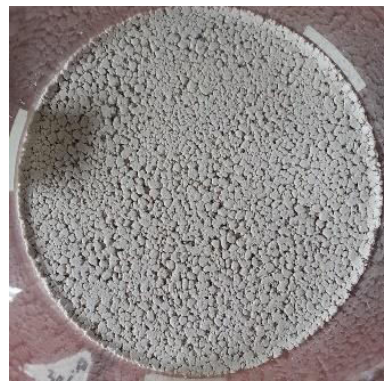

(a) Soil Sample 1 before vibration process

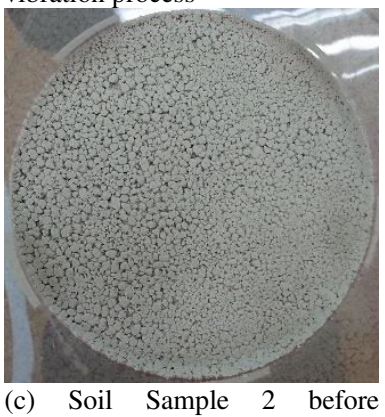

vibration process

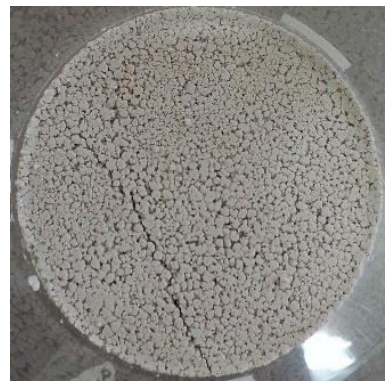

(b) Soil Sample 1 after vibration process with fractured

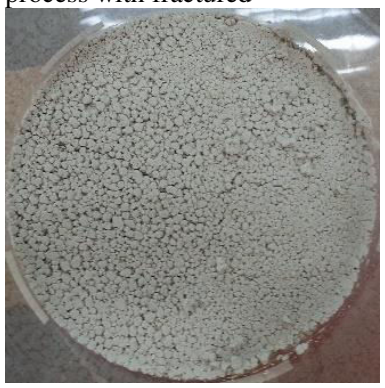

(d) Soil Sample 2 after vibration process with fractured
Figure 3 . The results of before and after vibration process for soil samples 1 and 2 with $30 \%$ moisture content

\section{B. Experimental Setup}

The intra-aggregated and inter-aggregated pores created through aggregation and vibration as previously explained represented the fractured double-porosity characteristic in the soil sample. The acrylic soil column containing fractured double-porosity soil was used to observe and measure the aqueous and non-aqueous phase liquids migration that occurs inside the entire circular column area with the purpose of not invading and not destroying the original soil sample setup. In each sample, the image acquisition setup for NAPLs migration is as shown in Figure 4.

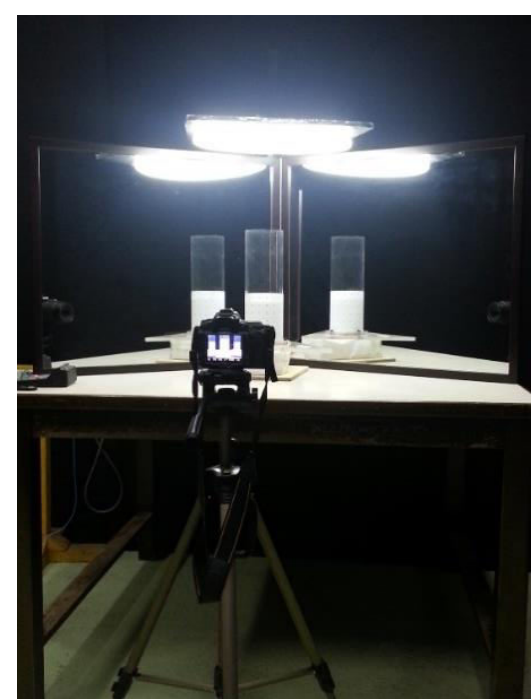

Figure 4. Digital image acquisition setup

The dominant equipment for APLs and NAPLs migration image acquisition system was the Nikon D90 DSLR digital camera and a V shape reflection mirror was used to reflect the whole image of circular column area. The Nikon D90 DSLR camera was fixed with medium size image format of $3216 \mathrm{x}$ 2136 pixels, which resulted in each pixel having the size of 5.6 $\mathrm{x} 5.6 \mu \mathrm{m}$. The setup of digital camera during the experiments 
was set at minimum shutter speed of 1/640 second and ISO speed set at ISO-2500, which has been implemented for all the soil sample experiments. To overcome the problem of insufficient image acquisition, this experiment used the $\mathrm{V}$ shape mirror that was adjusted until a clear image and the whole circular soil column area could be seen, allowing $100 \%$ of the circular soil column surface to be exposed in a single view of image acquisition throughout the experiments. Thus, the images of the APLs and NAPLs migration throughout the whole area of soil column circumference can be initially captured by just a single click on the DSLR digital camera. The light source for sample 1 and sample 2 come from linear fluorescent lamp-40 watt that was placed slightly above the circular soil column.

Both experiments were first sheathed in white paper with pre-drawn gridline $(20 \mathrm{~mm} \times 20 \mathrm{~mm})$ onto the soil column as a control point on the reference image. Once the reference image was taken, the pre-drawn gridline paper can be removed from the circular soil column. Both experiments began by pouring the dyed toluene instantaneously onto the top center of fractured aggregated soil sample in circular acrylic soil column. The quantity of $70 \mathrm{ml}$ dyed water and toluene was used in sample 1 and sample 2, respectively. After the dyed distilled water and toluene had covered the whole surface area of the fractured soil sample, the first digital image of dyed toluene migration was taken in a room temperature of $25^{\circ} \mathrm{C}$. The dyed liquids migration pattern at a specific time interval was captured for the rest of the subsequent digital images. The subsequent digital images, totaled 139 images in 60 minutes for sample 1 and 80 images in 5 minutes for sample 2 .

\section{Digital Image Processing Setup}

The recorded images in JPEG format then were transferred from digital camera to computer for further image processing using Surfer Software and Matlab routine. The first step in using Surfer Software is to digitize the control points for the area of interest on reference image to extract the control point image coordinates. Area of interest, referred to as predetermined migration boundary area ( $\mathrm{V}$ shape refection image and front image) for sample 1 and sample 2, contained the dyed toluene as shown in Figure 5. The image transformation required the coordinate of the control points and the true grid coordinate on pre-drawn grid lines).

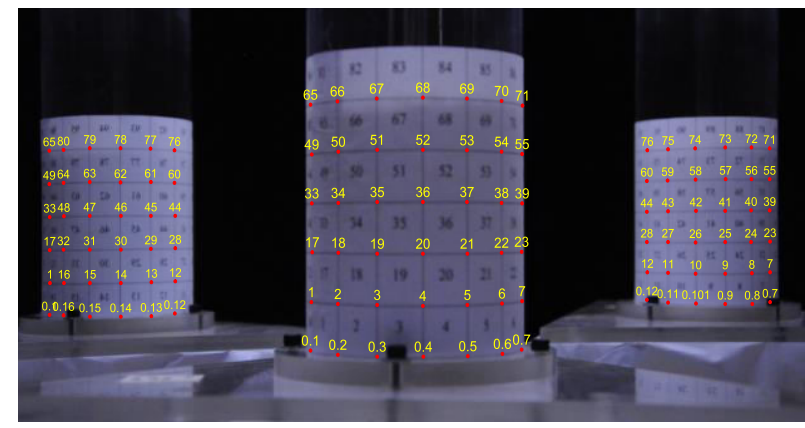

Figure 5. Control point position on reference image cover the area of interest for $\mathrm{V}$ shape reflection image and front image

Once the image control point has completed, Matlab routine was used to convert data from area of interest into hue saturation intensity digital image format and red-green-blue. The hue saturation intensity value and red-green-blue value from image were extracted and saved in text files using American Standard Code for Information Interchange format. Furthermore, Matlab routine was used to loop the subsequent digital image three times to extract and save the intensity values for all three section areas of interest (V shape refection image count as one and two section and front image count as three section) of the circular acrylic soil column. Finally, Surfer Software was used to plot the contour behaviour pattern of dyed toluene migration based on the hue saturation intensity values. The hue saturation intensity contour plot of dyed toluene migration behaviour can provide detailed information to facilitate researchers to understand the pattern of dyed toluene migration characteristic.

\section{RESULTS AND DISCUSSION}

The results after the APLs and NAPLs migration process for the top soil surface with the divided measurement of actual size column circumference zone for sample 1 and sample 2 to visualize the crack position is shown in Figure 6.

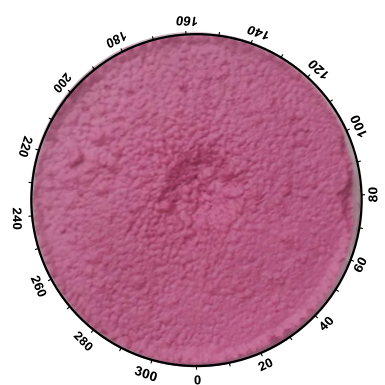

a) Soil sample 1 (APLs)

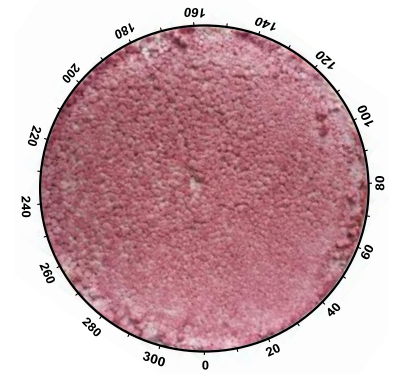

b) Soil sample 2 (NAPLs)
Figure 6. APLs and NAPLs migrated soil surface with measurement of actual column circumference zone

The downward migration pattern of HSI plot of dyed APL and NAPL in the fractured double-porosity soil sample with $30 \%$ moisture content for sample 1 and sample 2, respectively are shown in Figures 7 and 8 . When the HSI plot in curve connect the right and left boundary has formed the circular shape was clearly apparent in two-dimensional shape; however, the actual aqueous and non-aqueous phase liquid migration in the circular acrylic soil column was one-dimensional. Both samples used $70 \mathrm{ml}$ dyed APLs and NAPLs was poured instantaneously on top of the soil samples surface by using glass funnel to ensure that the dyed APLs and NAPLs penetrated in one-dimension. The dyed APLs and NAPLs would have migrated into the test sample before the whole soil sample surface was covered.

In sample 1, the selected HSI plots of dyed NAPLs migration are recorded at intervals such as $0.5,6,20$, and 60 minutes, respectively was selected for dyed water migration HSI plots as can been seen in Figure 7. Based on observation and the HSI intensity contour plot results, the flow of dyed water migration did not consistently penetrate the front $\mathrm{x}$-axis horizontal line as the fractured double-porosity soil was nonhomogenous. Rapid migration occurred at the cracked soil surface condition compared to locations that were not cracked 
in soil surface as shown in Figure 6. For the dyed water to completely recede from view on the whole top soil surface area into the fractured soil sample of the test took about 20 minute. Meanwhile, the overall duration for dyed water migration from the top surface to the stop point was 60 minutes and further observation at 120 minutes showed no changes in migration pattern where the dyed water migration between 90 to $140 \mathrm{~mm}$ along the $\mathrm{x}$-axis have been reached approximately $85 \%$ downward depth of the soil column. At 0.5 minute after the commencement of the experiment, the dyed APL migration reached halfway of the test sample at the location of fractured soil surface as shown in Figure 7. The dyed APL migrated fastest between 60 to $190 \mathrm{~mm}$ and 250 to $280 \mathrm{~mm}$ along the soil column circumference zone. The deepest downward migration depth along the soil column was $85 \mathrm{~mm}$. The dyed water migration stopped at 60 minutes in this study because the water viscosity was $0.00089 \mathrm{~kg} / \mathrm{m} / \mathrm{s}$, while toluene viscosity was $0.00055 \mathrm{~kg} / \mathrm{m} / \mathrm{s}$, indicating a viscosity difference of about 38\% [26] and [27]. Water has higher viscosity compares to toluene where the dyed water caused the high friction and resistance to gradual migration.
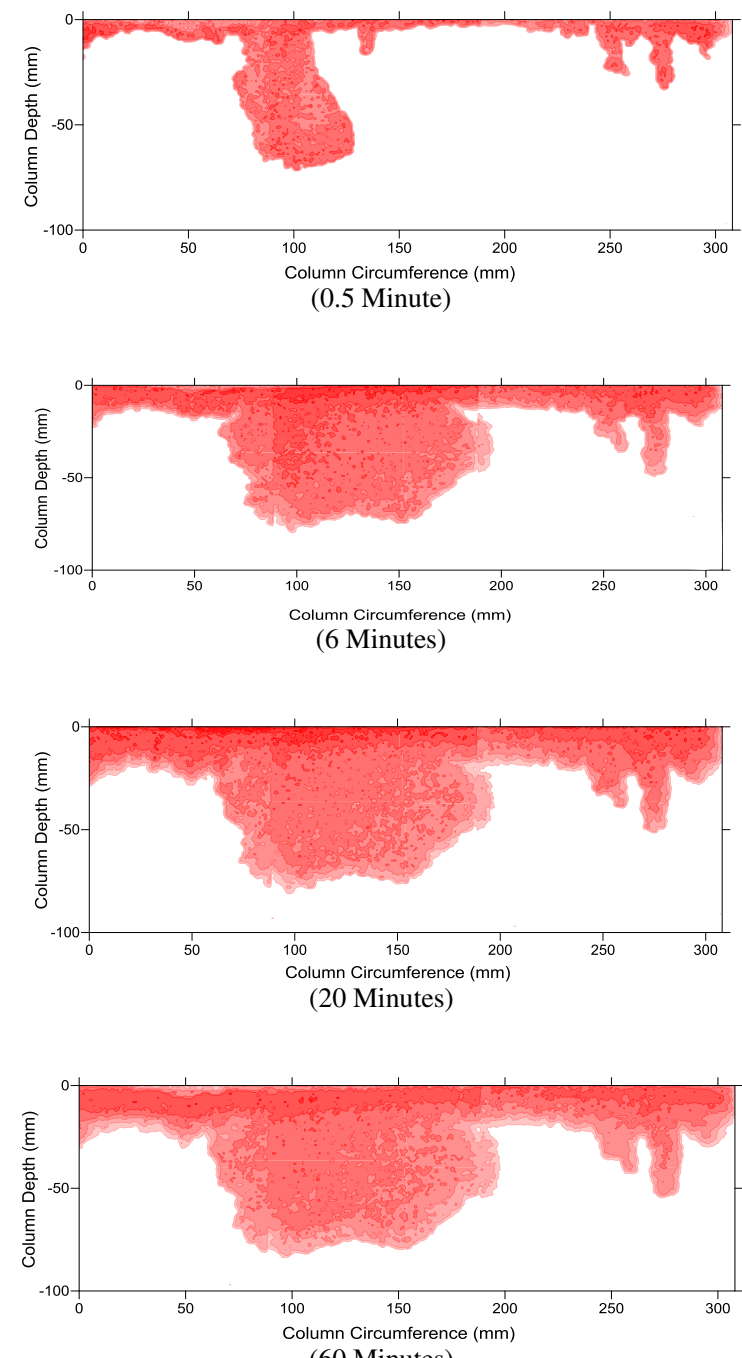

(60 Minutes)

Figure 7. HSI plots of downward dyed APL migration in fractured double-porosity soil for $30 \%$ moisture content
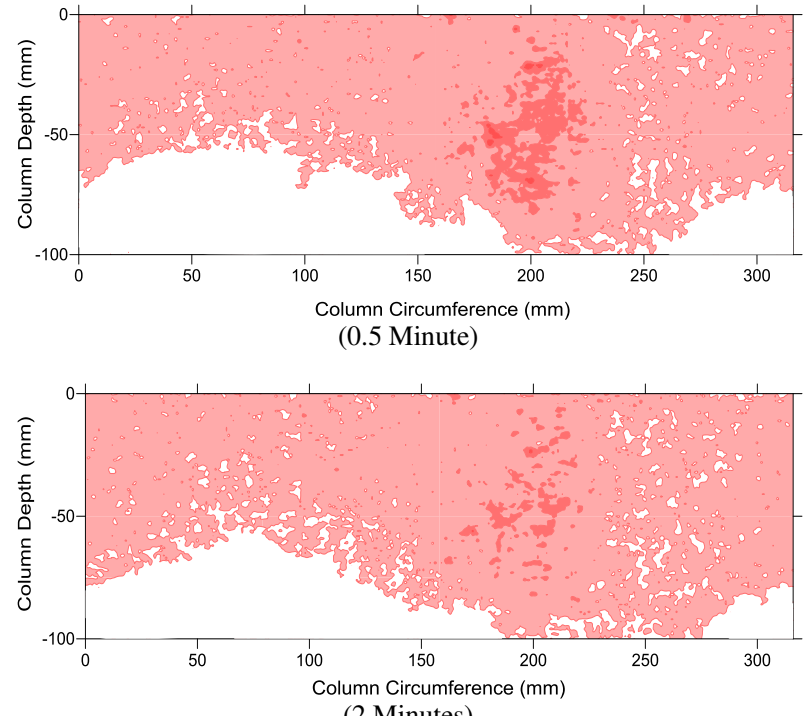

(2 Minutes)

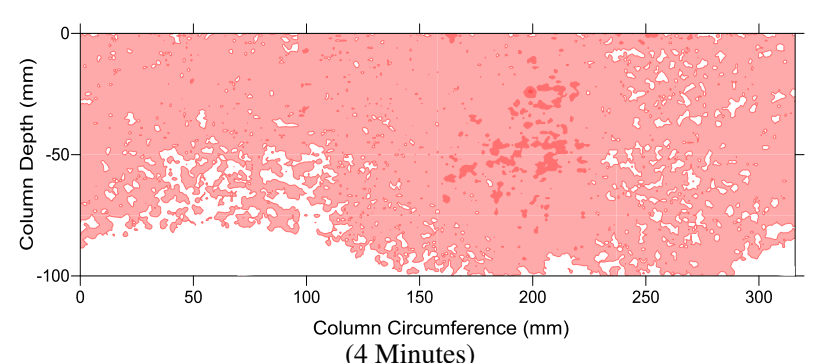

(4 Minutes)

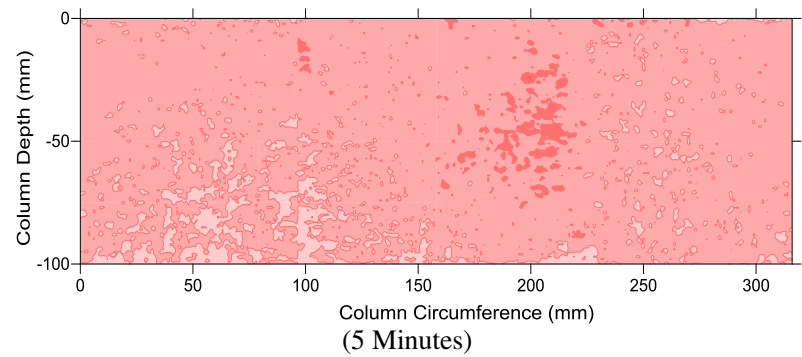

Figure 8. HSI plots of downward dyed NAPL migration in fractured double-porosity soil for $30 \%$ moisture content

In sample 2, the interval of $0.5,2,4,5$ minutes, respectively, was selected for dyed NAPL migration HSI plot as shown in Figure 8. The NAPL migration was similar to the result found in sample 1 . The flow of dyed NAPL migration was not uniformly downward at the front boundary horizontal line due to the nonhomogeneity of the fractured double-porosity soil structure. At 0.5 minute after the initiation of the experiment, the dyed NAPL migration reached three quarters through the test sample at the location of fractured soil surface as shown in Figure 6. The migration can be considered as one-dimensionally downward because the dyed NAPL poured on top of the test sample had covered the whole sample surface. It took about 4 seconds for the dyed NAPL to completely disappear from the whole top soil surface area into the fractured soil sample of the test. Meanwhile, the overall duration for dyed NAPL migration from the top surface to the bottom was 5 minutes and further observation at 30 minutes showed no changes in migration pattern where the NAPL migration fully reached the bottom of the soil column. From the result, it can identified and differentiated that soil sample 2 had the faster migration 
compared to soil sample 1 as less time was taken for liquid to reach the bottom of the soil column in soil sample 2. Furthermore, the difference between samples 1 and 2 was in the migration behaviour. For sample 2, $100 \%$ of NAPL migrated to the bottom of the soil column, whereas the liquid in sample 1 was not fully migrated to the soil column, stopping at $85 \%$ depth. The scenario occurred because the NAPL was immiscible liquid, while the APL was miscible liquid. Furthermore, the NAPL Toluene had lower viscosity compared to the APL water that had higher viscosity, therefore, dyed water caused the high friction and resistance to gradual migration.

Figures 9 and 10 present the measured values of dyed water and toluene saturation depth as a function of time for every $50 \mathrm{~mm}$ column circumference in experiment 1 and 2, respectively. From Figure 9, the cumulative saturation depth of dyed water migration at $100 \mathrm{~mm}$ column circumference displayed the fastest critical penetration within 0.5 minute as shown by the steepest gradient of the graph lines within that duration and continue to gradually incline horizontally until the end of the experiment. The second fastest critical penetration was at $90 \mathrm{~mm}$ column circumference within 0.5 minute as shown by the sharp gradient of the graph lines within that duration, and continue after 1 minute to gradually incline horizontally until the end of the experiment. At $150 \mathrm{~mm}$ column circumference was the third fastest critical penetration within 0.5 minute as shown by the sharp gradient of the graph lines within that duration, and continue to gradually decline from start until the end of the experiment. Meanwhile, the remaining column circumference positions display slightly decreased migration from start until the end of the experiment.

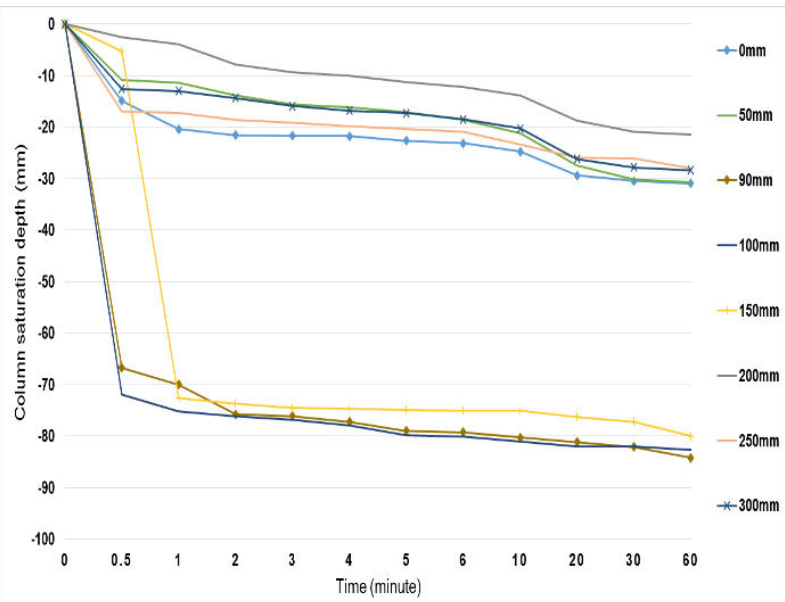

Figure 9. Measured values of dyed water saturation depth as a function of time for every $50 \mathrm{~mm}$ column circumference in sample 1

Based on Figure 10, the cumulative saturation depth of dyed water migration at $250 \mathrm{~mm}$ column circumference was the fastest critical penetration within 1 minute as demonstrated by the steepest gradient of the graph lines within that duration and after 1 minute began to slightly move downward until the end of the experiment. At $200 \mathrm{~mm}$ column circumference was the second fastest critical penetration within 1 minute as demonstrated by the sharp gradient of the graph line within that duration and continue after 1 minute to gradually incline horizontally until the end of the experiment. At $150 \mathrm{~mm}$ column circumference was the third fastest critical penetration within 1 minute as shown by the steepest gradient of the graph lines within that duration and after 1 minute began to gradually incline horizontally until the end of the experiment. Meanwhile, the remaining column circumference positions display slightly decreased migration from start until the end of the experiment

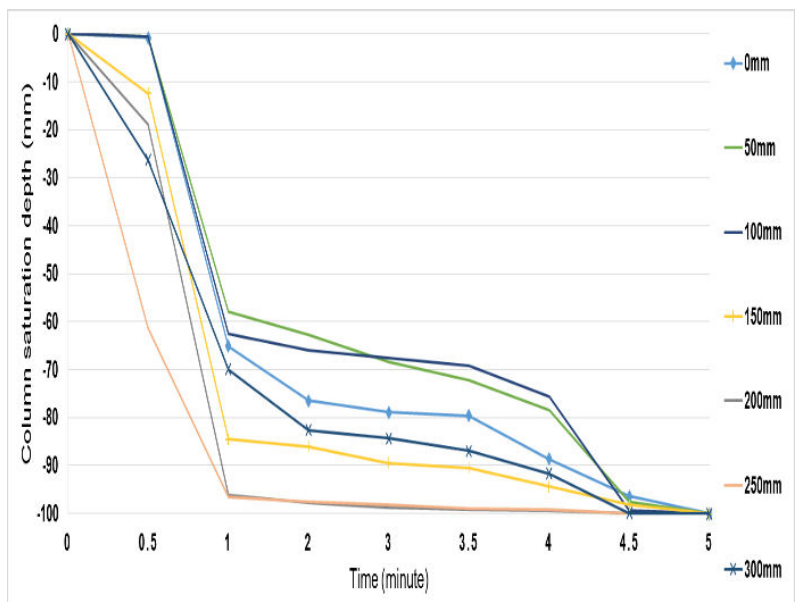

Figure 10. Measured values of dyed toluene saturation depth as a function of time for every $50 \mathrm{~mm}$ column circumference in sample 2

The calculated migration flow rate for the higher and overall average speed for every $50 \mathrm{~mm}$ column circumference zone was presented in Table 2. Sample 1 shows the higher migration flow rate from initial to 0.5 minute took position at $100 \mathrm{~mm}$ column circumference zone with the migration flow rate of $2.396 \mathrm{~mm} / \mathrm{s}$. Meanwhile, the other high migration flow rates occurred at $250 \mathrm{~mm}, 0 \mathrm{~mm}$ and $300 \mathrm{~mm}$ column circumference with the value of $0.567 \mathrm{~mm} / \mathrm{s}, 0.495 \mathrm{~mm} / \mathrm{s}$ and 0.418 $\mathrm{mm} / \mathrm{s}$, respectively. Thus, the overall average dyed water migration flow rate for sample 1 is $0.102 \mathrm{~mm} / \mathrm{s}$. At the $100 \mathrm{~mm}$ column circumference zone was the higher average migration flow rate with $2.396 \mathrm{~mm} / \mathrm{s}$ and also the deeper migration throughout the soil column depth with the depth height of $85 \mathrm{~mm}$. This could be because the worst fractured and cracked soil structure after the vibration was at the position of $100 \mathrm{~mm}$ based on the observation. Sample 2 displays the higher migration flow rate from initial to 0.5 minute took position at $250 \mathrm{~mm}$ column circumference zone with the migration flow rate of $61.403 \mathrm{~mm} / \mathrm{s}$. Meanwhile, the column circumference zone at $200 \mathrm{~mm}$ and $150 \mathrm{~mm}$ also have a high migration speed rate with the values of $18.837 \mathrm{~mm} / \mathrm{s}$ and 12.397 $\mathrm{mm} / \mathrm{s}$, respectively. The higher migration speed rate happened due to the fractured or cracked at soil sample surface as shown in Figure 6 for the actual column circumference. Therefore, the overall average dyed water migration flow rate for sample 2 is $4.389 \mathrm{~mm} / \mathrm{s}$. This scenario occurred because the re-compacted process during vibration due to the soil column boundary condition has strengthened the soil structure, which could slow down the migration flow rate. The higher average migration flow rate occurred at $250 \mathrm{~mm}$ column 
circumference zone with $61.403 \mathrm{~mm} / \mathrm{s}$ and the fully downward migration along the soil column depth with the depth height of $100 \mathrm{~mm}$. This could be caused by the greater capillary force exerted by the dyed liquid pressure on top surface of the soil sample that had not yet migrated through the sample surface.

Table 2. Migration flow rate for every $50 \mathrm{~mm}$ column circumference

\begin{tabular}{lcc|cc}
\hline Column & \multicolumn{3}{c}{ Migration Flow Rate (mm/s) } \\
\cline { 2 - 5 } Circumference \begin{tabular}{c} 
Sone $(\mathrm{mm})$ \\
\cline { 2 - 5 }
\end{tabular} & \multicolumn{2}{c}{ Soil sample 1 } & \multicolumn{2}{c}{ Soil sample 2 } \\
& (APLs) & \multicolumn{2}{c}{ (NALs) } \\
\cline { 2 - 5 } & Higher & Average & Higher & Average \\
& Flow & Flow for & Flow & Flow for \\
& Between & All the & Between & All the \\
& Initial to & Time & Initial to & Time \\
& 0.5 & Interval & 0.5 & Interval \\
& Minute & & Minute & \\
\hline 0 & 0.495 & 0.067 & 0.837 & 2.833 \\
50 & 0.360 & 0.048 & 0.598 & 2.522 \\
100 & 2.396 & 0.236 & 0.597 & 2.703 \\
150 & 0.174 & 0.224 & 12.397 & 4.579 \\
200 & 0.086 & 0.026 & 18.837 & 5.586 \\
250 & 0.567 & 0.059 & 61.403 & 9.145 \\
300 & 0.418 & 0.050 & 11.946 & 3.353 \\
\hline
\end{tabular}

From the result, it can be concluded that the sample 1 column circumference positions at $90 \mathrm{~mm}, 100 \mathrm{~mm}$, and $150 \mathrm{~mm}$ was the faster migration flow and the faster migration flow for sample 2 was at $150 \mathrm{~mm}, 200 \mathrm{~mm}$, and $250 \mathrm{~mm}$ could refer to the actual column circumference positions as shown in Figure 6. The average migration flow rate for soil sample 2 is faster than soil sample 1 . From the experiment result, the APLs migration was slower than the NAPLs migration flow rate because the viscosity was different. This could also be because of the physical bonding between water and soil attributed to Van Der Waals Force, which are weaker than hydrogen bonding. Thus, the hydrogen bonding has stronger physical bonding between water and soil. This was also one of the reasons why the APLs did not fully migrate to the bottom of soil column. In addition, the water migration flow rate was slower compared to toluene migration flow rate. Therefore, the factors that significantly influenced the dyed water migration in soil samples 1 and 2 was the fractured pattern of the soil sample, physical bonding between soil and liquids, and the capillary pressure of the liquid.

\section{CONCLUSION}

A physical laboratory experiment on APL and NAPL migration in fractured double-porosity soil with $30 \%$ moisture content had been carried out. This experiment was designed to investigate the APL and NAPL behaviour and to differentiate the pattern and flow rate in the fractured double-porosity soil in circular soil column. The digital image processing technique using Matlab routine and Surfer Software was applied to analyze the APL and NAPL migration data obtained from captured digital image. The physical laboratory experiment successfully provided the results of various behaviours and differentiated the pattern and flow rate of APL and NAPL migration at $30 \%$ moisture content. From the results observed, both experiments indicated that the
NAPL migrated faster from top to the bottom of soil column compared to APL migration. Meanwhile, the NAPL have $100 \%$ fully migrated to the bottom of the soil column but the APL migration stopped at $85 \%$ of the soil sample depth. Furthermore, the NAPL flow rate $(4.389 \mathrm{~mm} / \mathrm{s})$ was higher compared to APL flow rate $(0.102 \mathrm{~mm} / \mathrm{s})$. The results proved that the factors that significantly influenced the APL and NAPL migration in soil sample 1 and soil sample 2 was the fractured pattern of the soil sample, viscosity of liquid, the structure of the soil sample and the capillary pressure of liquid. In conclusion, the hue saturation intensity value and contour plot of dyed toluene migration could produce detailed particulars to professionals to understand and simulate the behaviour of APL and NAPL migration that could be used to identify the remediation method to sustainable of groundwater utilization.

\section{ACKNOWLEDGMENTS}

This study was supported by the Research Management Centre (RMC), Universiti Teknologi Malaysia under Research University Grant - Tier 1 (PY/2016/06547) from the Ministry of Higher Education Malaysia. The authors would also like to thank their respective University, Public Service Department Malaysia, Geotechnical Laboratory, Hydraulic and Hydrology Laboratory, Engineering Seismology and Earthquake Engineering Research Group (eSEER), and Survey Unit, Faculty of Civil Engineering, Universiti Teknologi Malaysia for kind assistance lent to this research. The first author was supported through the federal training award by the Public Service Department under Prime Minister's Department, Malaysia.

\section{REFERENCES}

[1] V. Muguntan, S. Ruben and L. Stephanie. (2015, June 5). Strong Earthquake Strikes Sabah (The Star) [Online]. Available

http://www.thestar.com.my/news/nation/2015/06/05/sabahquake/.

[2] K. F. Loke, N. A. Rahman and R. Nazir, "Experimental study on unsaturated double-porosity soil phenomena under vibration effect," J. Teknologi, vol. 79(4), pp. 65-72, 2017.

[3] D. G. Fredlund, S. L. Houston, Q. Nguyen and M. D. Fredlund, "Moisture movement through cracked clay soil profiles," Geotechnical and Geological Engineering, vol. 28(6), pp. 865-888, 2010.

[4] S. Krisnanto, H. Rahardjo, D. G. Fredlund and E. C. Leong, "Mapping of cracked soils and lateral water flow characteristics through a network of cracks,". Eng. Geology, vol. 172, pp. 12-25, 2014.

[5] X. Li and L. M. Zhang, "Characterization of dual-structure pore-size distribution of soil," Canadian Geotechnical J., vol. 46, pp. 129-141, 2009.

[6] A. El-Zein, J. P. Carter and D. W. Airey, "Threedimensional finite elements for the analysis of soil contamination using a multiple-porosity approach," Int. J. for Numerical and Analytical Methods in Geomechanics, vol. 30(7), pp. 577-597, 2006.

[7] R. Sa`ari, N. A. Rahman, N. H. Latif Abdul, Z. M. Yusof, S. K. Ngien, S. A. Kamaruddin, M. Mustaffar and M. A. Hezmi, "Application of digital image processing technique in monitoring LNAPL migration in double porosity soil column," J. Teknologi, vol. 3(72), pp. 23-29, 2015. 
[8] D. L. Lakeland, A. Rechenmacher and R. Ghanem, "Towards a complete model of soil liquefaction: the importance of fluid flow and grain motion," Proc. of the Roy. Soc. A: Math., Physical and Eng. Sci., London, 2014, A470:20130453.

[9] C. Masciopinto, M. Benedini, S. Troisi and S. Straface, Conceptual models and field test results in porous and fractured media in groundwater pollution control. Southampton, UK: WIT Press, 2001.

[10] G. I. Barenblatt, P. I. Zheltov and I. N. Kochina, "Basic concepts in the theory of seepage of homogeneous liquids in fissured rocks [strata]," J. of Applied Math. and Mechanics, vol. 24(5), pp. 1286-1303, 1960.

[11] K. F. Loke, N. A. Rahman and M. Z. Ramli, "A laboratory study of vibration effect for deformable double-porosity soil with different moisture content," Malaysian J. of Civil Eng., vol. 28 SI(3), pp. 207-222, 2016.

[12] J. Lewandowska, A. Szymkiewicz, W. Gorczewska and M. Vauclin, "Infiltration in a double-porosity medium: Experiments and comparison with a theoretical model," Water Resources Research, vol. 41(2), pp. W02022, 2005.

[13]A. R. Bagherieh, N. Khalili, G. Habibagahi and A. Ghahramani, "Drying response and effective stress in a double porosity aggregated soil," Eng. Geology, vol. 105(1-2), pp. 44-50, 2009.

[14]M. Y. D. Alazaiza, S. K. Ngien, M. M. Bob, S. A. Kamaruddin and W. M. F. Ishak, "Influence of macropores on DNAPL migration in double-porosity soil using light transmission visualization method," Transport in Porous Media, vol. 117, pp. 103-123, 2017.

[15] S. K. Ngien, P. Q. Chin, M. Hasan, M. I. Ali, M. Y. M. Tadza and N. A. Rahman, "Image analysis of non-aqueous phase liquid migration in aggregated kaolin," $A R P N J$. of Eng. and Applied Sci., vol. 11(10), pp. 6393-6398, 2016.

[16]E. A. Sitthiphat and Y. Siam, "Investigation of average optical density and degree of liquids saturation in sand by image analysis method," KKU Eng. J., vol. 43(S1), pp. 147-151, 2016.

[17]Z. Peng, C. Duwig, P. Delmas, J. P. Gaudet, A. G. Strozzi, P. Charrier and H. Denis, "Visualization and characterization of heterogeneous water flow in doubleporosity media by means of X-ray computed tomography," Transport in Porous Media, vol. 110, pp. 543-564, 2015.
[18] A. Luciano, P. Viotti and M. P. Papini, "Laboratory investigation of DNAPL migration in porous media," $J$. of Hazardous Materials, vol. 176, pp. 1006-1017, 2010.

[19]B. Agaoglu, N. K. Copty, T. Scheytt and R. Hinkelmann, "Interphase mass transfer between fluids in subsurface formations: A review," Advances in. Water Resources, vol. 79, pp. 162-194. 2015

[20] V. Cnudde and M. Boone, "High-resolution X-ray computed tomography in geosciences: A review of the current technology and applications," Earth Sci. Reviews, vol. 123, pp. 1-17, 2013.

[21]F. Zheng, Y. Gao, Y. Sun, X. Shi, H. Xu and J. Wu, "Influence of flow velocity and spatial heterogeneity on DNAPL migration in porous media: Insights from laboratory experiments and numerical modelling," Hydrogeology J., vol. 23, pp. 1703-1718, 2015.

[22] M. M. Bob, M. C. Brooks, S. C. Mravik and A. L. Wood, "A modified light transmission visualization method for DNAPL saturation measurements in 2-D models," Advance Water Resource, vol. 31, pp. 727-742, 2008.

[23] M. Oostrom, J. H. Dane and T. W. Wietsma, "A review of multidimentional, multifluid, intermediate-scale experiments: Flow behaviour, saturation imaging and tracer detection and quantification," Vadose Zone J., pp. 570-598, 2007.

[24] H. G. Maas and U. Hampel, "Photogrammetric techniques in civil engineering material testing \& structure monitoring," Photogrammetric Eng. \& Remote Sensing, vol. 72(1), pp. 39-45, 2006.

[25] S. K. Ngien, N. A. Rahman, K. Ahmad and R. W. Lewis, "A review of experimental studies on double-porosity soils," Scientific Research and Essays, vol. 7(38), pp. 3243-3250, 2012.

[26] M. J. Assael, H. M. T. Avelino, N. K. Dalaouti, J. M. N. A. Fareleira, and K. R. Harris, "Reference correlation for the viscosity of liquid toluene from 213 to $373 \mathrm{k}$ at pressures to 250Mpa," Int. J. of Thermophysics, vol. 22(3), pp. 789799, 2001

[27] K. Joseph, S. Mordechai and A. W. William, "Viscosity of liquid water in the range $8^{\circ} \mathrm{C}$ to $150^{\circ} \mathrm{C}, " J$. Physical and Chemical Reference Data, vol. 7(3), pp. 941-948, 1978. 